Provided for non-commercial research and education use. Not for reproduction, distribution or commercial use.

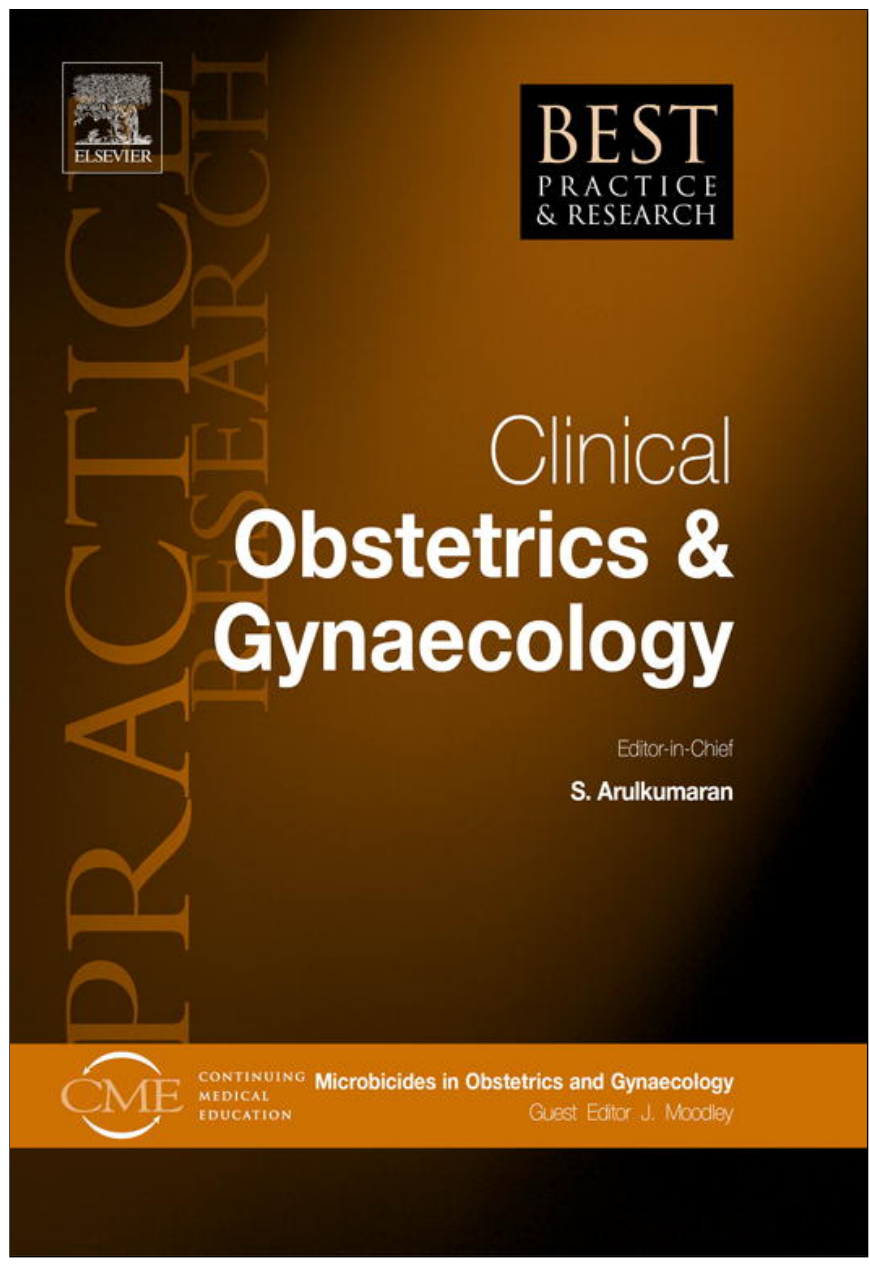

This article appeared in a journal published by Elsevier. The attached copy is furnished to the author for internal non-commercial research and education use, including for instruction at the authors institution and sharing with colleagues.

Other uses, including reproduction and distribution, or selling or licensing copies, or posting to personal, institutional or third party websites are prohibited.

In most cases authors are permitted to post their version of the article (e.g. in Word or Tex form) to their personal website or institutional repository. Authors requiring further information regarding Elsevier's archiving and manuscript policies are encouraged to visit:

http://www.elsevier.com/copyright 


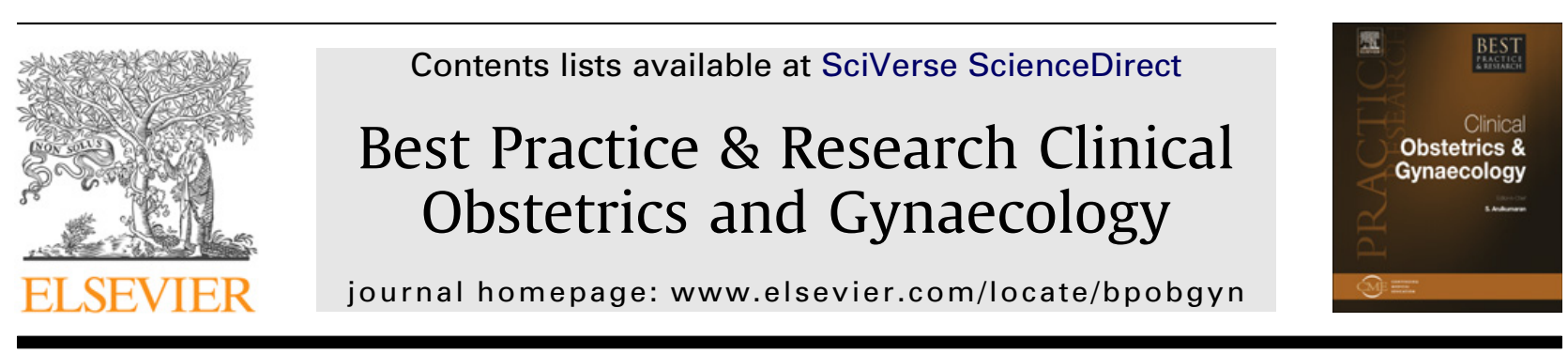

7

\title{
Implementing microbicides in low-income countries
}

\author{
Tanuja N. Gengiah, M.Clin.Pharm, MS(Epi) a , Quarraisha Abdool Karim, \\ PhD, Professor ${ }^{\mathrm{a}, \mathrm{b}, *}$ \\ ${ }^{a}$ CAPRISA - Centre for the AIDS Programme of Research in South Africa, University of KwaZulu-Natal, Private Bag X7, Congella, \\ Durban 4013, South Africa \\ ${ }^{\mathrm{b}}$ Department of Epidemiology, Columbia University, New York, USA
}

Keywords:

microbicides

implementation

low income countries

HIV prevention

\begin{abstract}
The magnitude of the global human immunodeficiency virus (HIV) epidemic is determined by women from lower income countries, specifically sub-Saharan Africa. Microbicides offer women who are unable to negotiate safe sex practices a self-initiated HIV prevention method. Of note, is its potential to yield significant public health benefits even with relatively conservative efficacy, coverage and user adherence estimates, making microbicides an effective intervention to invest scarce healthcare resources. Existing healthcare delivery systems provide an excellent opportunity to identify women at highest risk for infection and to also provide an access point to initiate microbicide use. Innovative quality improvement approaches, which strengthen existing sexual reproductive health services and include HIV testing, and linkages to care and treatment services, provide an opportunity to lay the foundations for wide-scale provision of microbicides. The potential to enhance health outcomes in women and infants and potentially affect rates of new HIV infection may soon be realised.
\end{abstract}

(c) 2012 Elsevier Ltd. All rights reserved.

\section{Introduction}

Women feature more strongly in this decade of the HIV pandemic than the previous two. Young women in sub-Saharan Africa ${ }^{1}$ and in the USA ${ }^{2}$ are disproportionately affected by human immunodeficiency virus (HIV) compared with their male counterparts. More than one-half of all global HIV infections are in women infected primarily through sexual transmission.

\footnotetext{
* Corresponding author. CAPRISA - Centre for the AIDS Programme of Research in South Africa, University of KwaZulu-Natal, Private Bag X7, Congella, Durban 4013, South Africa. Tel.: +27 31260 4550; Fax: +27 312604549.

E-mail address: abdoolq2@ukzn.ac.za (Q. Abdool Karim).
} 
Women's vulnerability to HIV infection is a result of a complex interplay of social, cultural, biological, political and economic factors. ${ }^{3}$ Current HIV prevention options are mainly dependent on male partner co-operation. Power disparities between men and women limit the ability of women to negotiate safer sex practices, and this is particularly pronounced for young women under 20 years of age. $^{4,5}$ In the absence of an effective vaccine, other approaches that reduce new HIV infections, even if moderately effective, are urgent. ${ }^{6}$

To this end, investment in the development of microbicides has occurred over the past 17 years, and efforts are designed to enable women to control their HIV risk through a self-initiated method. The CAPRISA $004,1 \%$ tenofovir gel trial ${ }^{7}$ provided the first evidence that such a technology was within our reach. This antiretroviral agent specifically formulated for topical application in the female genital tract has limited systemic toxicities. If effectiveness is confirmed in the FACTS 001 trial, ${ }^{8,9}$ tenofovir gel may fill an important HIV prevention gap for women in the next 3-5 years. Mathematical modelling data based on the CAPRISA 004 trial findings, ${ }^{7,10}$ indicates that, over 20 years, the use of tenofovir gel in South Africa alone could avert up to 2 million new infections and 1 million deaths from acquired immune deficiency syndrome (AIDS), which would significantly affect the epidemic in South Africa. ${ }^{10}$ Tenofovir gel use in more than $25 \%$ of sexual encounters could significantly alter the course of the epidemic in southern Africa, and thereby globally.

Further down the microbicide development pipeline, we anticipate additional products with greater efficacy through enhanced drug-delivery mechanisms such as vaginal rings, sustained-release formulations, synergistic drug combinations, ${ }^{11}$ and multi-purpose technologies that, for example, combine fertility control and HIV risk-reduction needs. Antiretroviral-based microbicides are now seen as the future of HIV control. ${ }^{12}$

It is at this critically important stage, and before product licensure, that we ask the difficult implementation questions. These include determining the potential barriers to access and uptake, and how to best incorporate this prevention strategy into existing healthcare delivery systems to maximise access to women in resource-limited settings who can benefit most from such technologies expeditiously. ${ }^{13,14}$

\section{Do microbicides meet the criteria for an effective intervention?}

Resources for meeting healthcare needs in low-income countries are limited. Introduction of new technologies and innovations have to be cognisant of this, and careful attention needs to be paid to criteria used to determine public health benefits of new interventions for optimal, efficient and effective use of limited resources. ${ }^{14}$

Given the recent advances in evidence-based HIV prevention approaches to reduce sexual transmission of HIV and the diversity of HIV epidemics geographically, populations at risk, levels of efficacy and healthcare delivery infrastructure, ${ }^{15}$ Shelton ${ }^{16}$ proposed a useful framework comprising 20 criteria to guide decision-making on use of scarce health resources in developing countries. ${ }^{16}$ We have adapted this guide to assess if microbicides have the potential to meet the criteria for an effective intervention. The criteria used are presented in Table $1 .{ }^{16}$

\section{Potential barriers and models for implementing microbicides in low-income countries}

The microbicide development pipeline is in various stages of testing of different candidate products ranging from the pre-clinical stage to phase 1 to 3 studies. ${ }^{17}$ Several immediate barriers exist for implementation (Fig. 1). The first major barrier to be overcome is the identification of a safe and effective candidate agent. Thus far, only one microbicide trial has been successful in proving effectiveness. After establishing effectiveness, the regulatory pathway will require in-country licensing and registration of the candidate agent. It is unclear how lengthy this process will be. Health systems from lower income countries will also need to absorb the human resource and infrastructure requirements of microbicide provision. Use of innovative approaches such as quality improvement approaches (described later) needs to be part of health systems' strategic planning efforts. Lastly, sustained production of microbicides will require long-term investment and possibly in-country capacity for production. 
Table 1

Criteria for an effective human immunodeficiency virus prevention microbicide intervention.

\begin{tabular}{|c|c|}
\hline Criterion & Comment \\
\hline $\begin{array}{l}\text { Health burden in low-income } \\
\text { countries }\end{array}$ & $\begin{array}{l}\text { High HIV burden; HIV prevention is a health priority; women younger than 24years } \\
\text { have three- to six-fold higher rates of HIV infection compared with men. }\end{array}$ \\
\hline Individual efficacy & $\begin{array}{l}\text { First trial with tenofovir gel shows } 39 \% \text { effectiveness, but could be as high } 54 \% \text { with } \\
\text { higher adherence. Most trials aim for at least } 50 \% \text { higher efficacy than placebo. }\end{array}$ \\
\hline Scalability & $\begin{array}{l}\text { Will benefit individual and reach scale by reducing transmissions within sexual } \\
\text { networks. }\end{array}$ \\
\hline Low cost & Cost issues will exist at initial production but likely to be reduced over time. \\
\hline Simplicity & $\begin{array}{l}\text { Fairly simple to administer but requires training at initiation and HIV and pregnancy } \\
\text { requires on-going monitoring. }\end{array}$ \\
\hline Safety & Safe with low systemic absorption; anticipate a good risk - benefit profile. \\
\hline User acceptability & $\begin{array}{l}\text { Microbicides have high user acceptability in trial settings; unable to date to test in real- } \\
\text { world settings. }\end{array}$ \\
\hline Family acceptability & $\begin{array}{l}\text { Can be used without partner knowledge; some data available to support family } \\
\text { acceptability. }\end{array}$ \\
\hline Social norms & $\begin{array}{l}\text { Limited community level data available that support microbicides. Advocacy efforts } \\
\text { need to be strengthened. }\end{array}$ \\
\hline Provider/medical culture & Motivation to avert HIV infection is high in countries burdened with disease. \\
\hline Potential for integration & $\begin{array}{l}\text { Excellent potential for integration into existing services, particularly sexual } \\
\text { reproductive health and pre- and post-natal services. }\end{array}$ \\
\hline Alternative approaches & $\begin{array}{l}\text { Limited prevention options exist for women; none that are women-initiated and } \\
\text { controlled. }\end{array}$ \\
\hline $\begin{array}{l}\text { Regulatory and policy } \\
\text { requirements }\end{array}$ & $\begin{array}{l}\text { Regulators such as the US Food and Drug Administration have agreed to fast-track } \\
\text { microbicide candidates for registration; need sufficient efficacy and safety data for } \\
\text { licensure; at least one other confirmatory trial; FACTS } 001 \text { is under way to confirm } \\
\text { CAPRISA 004. }\end{array}$ \\
\hline Procurement and logistics & $\begin{array}{l}\text { Many low-income countries gaining experience with antiretroviral treatment and } \\
\text { preventing mother-to-child transmission scale-up; systems are in place to address this; } \\
\text { the South African government holds royalty-free license and is already exploring } \\
\text { manufacturing options, market stratification and access across Africa. }\end{array}$ \\
\hline Timing dependency & $\begin{array}{l}\text { Only coitally administrated use has been tested to date; in the future we are likely to } \\
\text { have multiple formulations and delivery vehicles, including vaginal rings and multi- } \\
\text { purpose technologies. }\end{array}$ \\
\hline Durability & $\begin{array}{l}\text { Low durability; will need to be provided repeatedly; frequency could vary in the future } \\
\text { based on formulation and delivery vehicle. }\end{array}$ \\
\hline Behaviour dependency & $\begin{array}{l}\text { A challenge; needs to be incorporated into current behaviour; new method that will } \\
\text { need intense support initially and less with time. }\end{array}$ \\
\hline $\begin{array}{l}\text { Commercial sector } \\
\text { compatibility }\end{array}$ & $\begin{array}{l}\text { Potential for socially responsible private-public partnerships; already in place in South } \\
\text { Africa. }\end{array}$ \\
\hline Collateral benefits & $\begin{array}{l}\text { Reduce maternal morbidity and mortality; avert infants infections, other sexually } \\
\text { transmitted infection and enhance sexual and reproductive health services; women } \\
\text { empowerment. }\end{array}$ \\
\hline Sustainability & Requires ongoing commitment and investment. \\
\hline
\end{tabular}

HIV, human immunodeficiency virus; adapted from Shelton $2011 .^{16}$

Translating positive findings from rigorous, small-scale, randomised-controlled trials into largescale healthcare systems in low-income countries poses many challenges. ${ }^{18}$ Model predictions for the variability in performance of prevention of mother-to-child transmission protocols, using hypothetical and reported data, demonstrate that highly effective combination antiretroviral treatment will only be marginally more effective than single-dose antiretroviral drugs unless health systems achieve high performance at each interaction in the prevention of mother-to-child transmission pathway. ${ }^{19} \mathrm{~A}$ similar threat exists for scale-up of effective microbicides without pre-emptive planning and preparation.

Health systems in developing countries are without doubt under severe strain from human resources, infrastructure and budgetary deficiencies, ${ }^{20}$ and exacerbated by advancing HIV disease and concomitant co-morbidities. A glimpse of this challenge was gleaned in the provision of antiretroviral treatment. Notwithstanding these challenges, existing health systems remain the main mechanism to close the evidence-implementation gap, ${ }^{21}$ and the only sustainable way to efficiently introduce microbicides for wide and effective coverage that translates into public health benefits. 


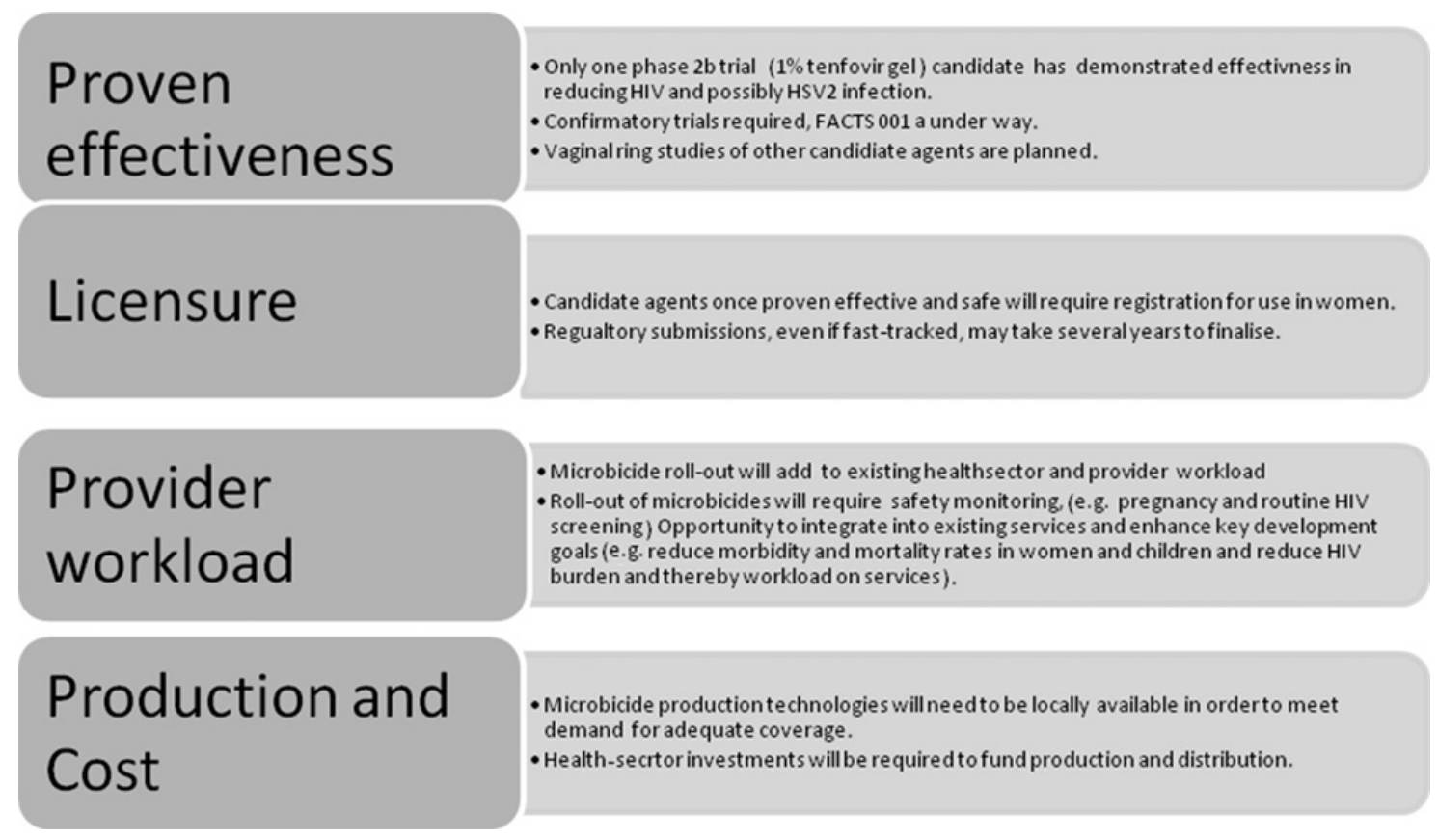

Fig. 1. Immediate barriers to implementing microbicides in low-income countries. HIV, human immunodeficiency virus; HSV2, herpes simplex virus 2 .

Implementation science is defined as 'the scientific study of methods to promote the integration of research findings and evidence-based interventions into healthcare policy and practice and hence improve the quality and effectiveness of health services and care. ${ }^{22}$ By definition, this type of engagement provides an appropriate framework for investigating the barriers to integration of new prevention methods into existing health systems, and develop innovative methodologies, such as the quality improvement approach to address challenges.

Thus far, the benefits of medical advances especially in developing countries have been held 'hostage' to our inability to bring to scale what we know works. Often, policies are formulated but little attention is paid to programmatic scale-up, training and support of healthcare providers, existing workloads, the diversity of needs in different healthcare settings that demand critical thinking, and troubleshooting on a day-to-day, client-to-client basis. One strategy to address this gap is the quality improvement approach. The quality improvement approach is premised on designing systems for maximum effectiveness, efficiency, and adaptability, and to actively disseminate the best models for health-service delivery at a rapid rate. Quality improvement aims to strengthen heath systems using small-scale, rapid cycles of improvement that are designed and implemented by local providers to develop reliable processes for service delivery through mentored coaching, re-enforcement and support. ${ }^{23-25}$ Using this approach, and with minimal additional resources, existing services could be substantially strengthened to introduce microbicides at scale. Importantly, individual skills-building acquired through the quality-improvement approach include critical thinking and problem solving that can have application to other system challenges. Application of the quality improvement approach to health systems of low-income countries has been tested and shows considerable potential. In South Africa, rapid scale-up of access to HIV care and treatment services, ${ }^{26}$ and reduced rates of mother-tochild transmission of HIV at a district level owing to improved coverage, ${ }^{27}$ have been demonstrated.

In order for women to benefit from HIV prevention interventions such as microbicides, it is critically important to be able to identify those uninfected and at high risk for infection. ${ }^{15}$ Existing healthcare infrastructure and human resources, such as those listed in Table 2, provides rational, extant and often overlooked opportunities for identification of at-risk women and also programmatic scale-up of microbicides and other combination prevention methods. Low-income countries are already investing heavily in test and treat campaigns, and it is critical to be able to capitalise on these opportunities as potential platforms from which microbicides can be launched. 
Table 2

Potential operational model entry points for microbicides scale up.

\begin{tabular}{ll}
\hline Existing model & Missed opportunities. \\
\hline $\begin{array}{l}\text { Family planning clinic within a } \\
\text { primary healthcare clinic } \\
\text { Primary healthcare clinic general }\end{array}$ & Contraception provision; PAP smear; condom provision. \\
& $\begin{array}{l}\text { Well-baby immunisation clinics; antenatal clinic; postnatal clinic; sexually } \\
\text { transmitted infection treatment; condom provision. }\end{array}$ \\
$\begin{array}{l}\text { Antiretroviral clinics } \\
\text { Retail pharmacy }\end{array}$ & $\begin{array}{l}\text { HIV screening. } \\
\text { Contraceptive dispensing; HIV screening; sexually transmitted infection drug }\end{array}$ \\
& dispensing; pregnancy testing or test kit purchase; condom sale. \\
\hline
\end{tabular}

HIV, human immunodeficiency virus.

Using the public sector family planning clinic model as a prototype for incorporation of microbicides provision, several advantages are immediately apparent: (1) large numbers of sexually active women already using regular, long-term, family planning services become accessible; (2) staff at the family planning clinics are trained on reproductive health and have prior knowledge and experience with adherence to medication support and counselling; (3) family planning clinics are often integrated in primary healthcare clinics that provide a minimum package of health services at no cost, and are widely available in South Africa; (4) family planning services, in addition to provision of contraception, also provide women with a sexual and reproductive health package that can include HIV risk reduction counselling, HIV testing, sexually transmitted disease screening, condom provision and pap smears Similar opportunities exist in pre-natal and post-natal clinic services.

Other concerns relating to scale up of antiretroviral agents used prophylactically, either in oral or topical formulations, relate to the potential for long-term, drug-adverse effects, emergence of drug resistance, adherence challenges that widen the efficacy-effectiveness gap and behavioural disinhibition. Currently, no clear evidence supports any of these potential concerns as reasons to halt development. It is critically important, however, that further opportunities for assessing these concerns are maximised in future research. These include careful monitoring of seroconvertors from prevention trials, natural-history studies that monitor drug resistant strains of virus, and study of disease progression and therapeutic outcomes once initiated on antiretroviral treatment. As with all new technologies, adherence support at initiation is more intensive and, over time, with greater product experience and confidence in effectiveness, adherence may be easier to facilitate. Post-trial access studies provide excellent opportunities to better understand these issues in a real-world setting.

\section{Conclusion}

Low-income countries bear a disproportionate burden of HIV infection. In sub-Saharan Africa, the HIV epidemic is of a generalised nature. Young women in these countries have three- to six-fold higher rates of HIV infection compared with men in the same age range, and have multiple sexual and reproductive health needs in addition to their HIV risk. Microbicides are promising new womeninitiated prevention technology. The CAPRISA 004, $1 \%$ tenofovir gel is an important first step in enhancing optimism in the microbicide development field. The confirmatory FACTS 001 trial could potentially lead to licensure of tenofovir gel in South Africa in the next 2-3 years. Modelling estimates indicate that a substantial number of HIV infections will be averted in South Africa even with a moderately effective product, used at least in one-quarter or more of all sex acts.

We provide a framework to evaluate the utility of microbicides as a public health tool. Additionally, we explore the product-development pathway and health-system barriers to access to a microbicide. We propose the use of innovative implementation sciences approaches, including the qualityimprovement approach to strengthen health systems and roll out a new intervention for public health benefit. We submit that using existing points of care, such as family planning clinics, to assess HIV risk will reduce missed opportunities to engage women at high risk for infection. The potential to initiate women on microbicides, when these become available, is enhanced by using existing services, infrastructure and human resources. 
It is likely with continued investments in microbicide development that the future will bring many more microbicide products with more convenient formulations and drug-delivery mechanisms to meet the multiple sexual and reproductive health needs of women. Now is the time to start to explore how to introduce these new technologies efficiently and effectively to women and ensure that history is not repeated by our inability to deliver expeditiously what we know works to those who need it most.

\section{Practice points}

- Microbicides have the potential to fill an urgent need for a woman-controlled HIV prevention method in low-income countries.

- Significant gaps exist between clinical-trial effectiveness and performance in real life.

- Missed opportunities to integrate prevention efforts into existing health-system models.

- Implementation sciences research needed to assess 'best practice models' for microbicides roll-out.

- Maximise opportunities to increase knowledge of HIV status, strengthen sexual and reproductive healthservices, links to care, and support to prepare the way to add new technologies as they advance to licensure.

\section{Research agenda}

- Confirmatory studies for licensure of $1 \%$ tenofovir gel.

- Continued investment to enhance efficacy through better formulations, delivery mechanisms and multi-purpose technologies.

- Implementation sciences research to generate empirical evidence for integrating an effective microbicides into healthcare services.

- Assessing and engaging with using quality-improvement methods.

- Bridging the gaps between knowledge generation and operationalisation of new evidence.

\section{Acknowledgments}

Quarraisha Abdool Karim is the Co-Principal investigator of the HPTN Prevention Leadership Group (NIH/NIAID U01AI068619) and Co-Principal Investigator of the CAPRISA 004 Tenofovir gel trial which is supported by the Center for the AIDS Program of Research in South Africa (CAPRISA), the United States Agency for International Development (USAID), FHI (cooperative agreement \#GPO-A-00-05-0002200, contract\#132119), and LIFElab, a biotechnology center of the South African Department of Science and Technology. The Columbia University-Southern African Fogarty AIDS International Training and Research Programme (AITRP grant \# D43TW00231) has supported Tanuja Gengiah's professional development.

\section{References}

1. UNAIDS. UNAIDS world AIDS day report 2011. Geneva: Joint United Nations Programme on HIV/AIDS, 2011, http://www. unaids.org/en/media/unaids/contentassets/documents/unaidspublication/2011/JC2216_WorldAIDSday_report_2011_en. pdf [last accessed 24.02.12].

2. Centres for Disease Control. HIV surveillance report: diagnoses of HIV infection and AIDS in the United States and dependent areas 2009, http://www.cdc.gov/hiv/surveillance/resources/reports/2009report/index.htm [last accessed 24.02.12].

3. Leclerc-Madlala S. Age-disparate and intergenerational sex in southern Africa: the dynamics of hypervulnerability. AIDS 2008; 22(Suppl. 4): S17-S25. 
4. Luke N. Age and economic asymmetries in the sexual relationships of adolescent girls in sub-Saharan Africa. Stud Fam Plann 2003; 34: 67-86.

5. Task force report on women and girls in southern Africa. Geneva: UNAIDS, 2004

6. Lagakos SW \& Gable AR. Challenges to HIV prevention: seeking effective measures in the absence of a vaccine [comment]. N Engl J Med 2008; 358: 1543-1545.

*7. Abdool Karim Q, Abdool Karim SS, Frohlich JA et al. Effectiveness and safety of tenofovir gel, an antiretroviral microbicide, for the prevention of HIV infection in women. Science 2010; 329: 1168-1174.

8. Vermund SH \& Van Damme L. HIV prevention in women [letter]: next steps. Science 2011; 331: 284.

9. ClinicalTrials.gov. FACTS 001: safety and effectiveness of tenofovir gel in the prevention of human immunodeficiency virus (HIV1) infection in young women and the effects of tenofovir gel on the incidence of herpes simplex virus (HSV-2) infection 24 October 2011, http://clinicaltrials.gov/ct2/show/NCT01386294?term=facts+001\&rank=1 [last accessed 24.02.12].

*10. Williams BG, Abdool Karim SS, Karim QA et al. Epidemiological impact of tenofovir gel on the HIV epidemic in South Africa. J Acquir Immune Defic Syndr 2011; 58: 207-210.

11. Verma NA, Lee AC, Herold BC et al. Topical prophylaxis for HIV prevention in women: becoming a reality. Curr HIV/AIDS Rep 2011; 8: 104-113.

*12. Karim SS \& Karim QA. Antiretroviral prophylaxis: a defining moment in HIV control. Lancet 2011; 378: e23-e25.

13. Underhill K, Operario D, Skeer M et al. Packaging PrEP to prevent HIV: an Integrated framework to plan for pre-exposure prophylaxis implementation in clinical practice. J Acquir Immune Defic Syndr 2010; 55: 8-13.

14. Underhill K, Operario D, Mimiaga MJ et al. Implementation science of pre-exposure prophylaxis: preparing for public use [review]. Curr HIV/AIDS Rep 2010; 7: 210-219.

*15. Shelton JD. HIV/AIDS. ARVs as HIV prevention: a tough road to wide impact. Science 2011; 334: 1645-1646.

*16. Shelton JD. Twenty criteria to make the best of scarce health resources in developing countries. BMJ 2011; $343: \mathrm{d} 7023$.

17. Kelly CG \& Shattock RJ. Specific microbicides in the prevention of HIV infection. J Intern Med 2011; 270: 509-519.

18. Padian NS, McCoy SI, Karim SS et al. HIV prevention transformed: the new prevention research agenda. Lancet 2011; 378: 269-278.

19. Barker PM, Mphatswe W \& Rollins N. Antiretroviral drugs in the cupboard are not enough: the impact of health systems' performance on mother-to-child transmission of HIV. J Acquir Immune Defic Syndr 2011; 56: e45-e48.

20. Frenk J, Chen L, Bhutta ZA et al. Health professionals for a new century: transforming education to strengthen health systems in an interdependent world. Lancet 2010; 376: 1923-1958.

*21. Frenk J. The global health system: strengthening national health systems as the next step for global progress. PLoS Med 2010; 7: e1000089.

*22. Schackman BR. Implementation science for the prevention and treatment of HIV/AIDS. J Acquir Immune Defic Syndr 2010; 55(Suppl. 1): S27-S31

*23. Berwick DM. Continuous improvement as an ideal in health care. $N$ Engl J Med 1989; 320: 53-56.

24. Richardson WC, Berwick DM \& Bisgard JC. The Institute of Medicine report on medical errors. N Engl J Med [letter] 2000; 343: 663-664.

25. Berwick DM. Disseminating innovations in health care. JAMA 2003; 289: 1969-1975.

*26. Barker PM, McCannon CJ, Mehta N et al. Strategies for the scale-up of antiretroviral therapy in South Africa through health system optimization. J Infect Dis 2007; 196(Suppl. 3): S457-S463.

*27. Doherty T, Chopra M, Nsibande D et al. Improving the coverage of the PMTCT programme through a participatory quality improvement intervention in South Africa. BMC Public Health 2009; 9: 406. 